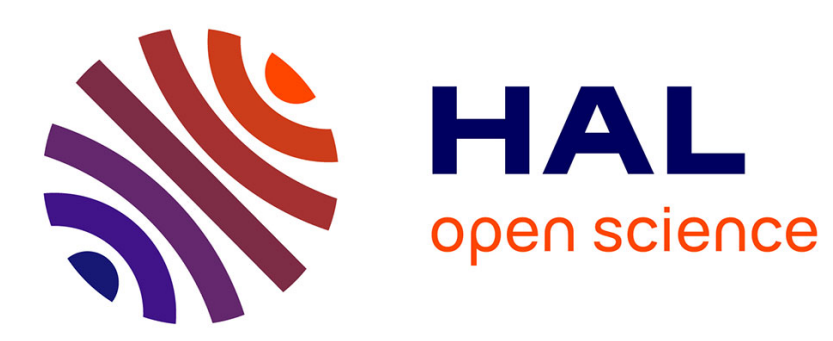

\title{
Defects of structure in one-dimensional trains of drops of alternating composition
}

\author{
Hirokazu Maruoka, Alexandre Schmit, Laurent Courbin, Pascal Panizza
}

\section{To cite this version:}

Hirokazu Maruoka, Alexandre Schmit, Laurent Courbin, Pascal Panizza. Defects of structure in onedimensional trains of drops of alternating composition. Microfluidics and Nanofluidics, 2016, 20 (5), pp.82. 10.1007/s10404-016-1745-y . hal-01326819

\section{HAL Id: hal-01326819 https://hal.science/hal-01326819}

Submitted on 6 Jun 2016

HAL is a multi-disciplinary open access archive for the deposit and dissemination of scientific research documents, whether they are published or not. The documents may come from teaching and research institutions in France or abroad, or from public or private research centers.
L'archive ouverte pluridisciplinaire HAL, est destinée au dépôt et à la diffusion de documents scientifiques de niveau recherche, publiés ou non, émanant des établissements d'enseignement et de recherche français ou étrangers, des laboratoires publics ou privés. 


\title{
Defects of structure in one-dimensional trains of drops of alternating composition
}

\author{
Hirokazu Maruoka, ${ }^{1}$ Alexandre Schmit, ${ }^{2}$ Laurent Courbin, ${ }^{2}$ and Pascal Panizza ${ }^{2}$ \\ ${ }^{1}$ Tokyo University of Agriculture and Technology (TUAT) Tokyo, Japan \\ ${ }^{2}$ Institut de Physique de Rennes (IPR), UMR CNRS 6251, Université Rennes 1, 35042 Rennes, France
}

\begin{abstract}
Merging two periodic droplet trains at a T-junction, we investigate the production of onedimensional (1D) trains of drops of alternating composition. The structure of these trains consists of a succession of well-defined patterns and defects. A discrete model recently introduced to describe the structure of double emulsions made with two-step microfluidic dripping techniques predicts the nature of these patterns and their scheme of arrangement in a train as functions of the rates at which the two droplet trains reach the junction. Millifluidic experiments validate these predictions.
\end{abstract}

\section{Introduction}

Microfluidic techniques allow for the steady production of nanoliter drops one by one and at high rates $(100 \mathrm{~Hz}-$ $1 \mathrm{KHz}$ ) with unprecedented controls of their size [1] and internal structure [2]. Used as the micron-sized analogs of test tubes, these drops make possible the miniaturization of laboratories on chips measuring just a few square inches and the development of high-throughput applications aiming for faster and better analyses than standard batch techniques [3, 4]. However, such achievements require integrating on a chip various tasks that are operating on individual drops, e.g. formation [5-7], dilution [8, 9], mixing [10-13], storage [14-17], fragmentation [18-22], sorting [23-25], or coalescence [26-29]. As a result, a lot of attention has been devoted in recent years to engineer efficient passive $[30,31]$ or active $[32-$ 35] modules performing such tasks.

In this context, the formation of $1 \mathrm{D}$ droplet trains is a crucial step for many microfluidic applications in various fields. In material science, double emulsions with two sets of internal compartments are commonly produced with two-step microfluidic dripping techniques. Briefly, a train of droplets of alternating composition and/or size flowing in an immiscible fluid is directed towards the inlet of a drop maker [36, 37] or the free extremity of a capillary tube [38] where periodically emitted drops encapsulate the droplets. This process produces a double emulsion over time. Another use of trains of alternating droplets concerns measurements of a key parameter controlling the kinetic stability of water-in-oil emulsions, i.e., the water transport rate in different oils [39]. Such experiments consist in generating alternating drops made of two aqueous solutions having different $\mathrm{NaCl}$ concentrations and flowing in oil inside a capillary tube [40]. Because of the osmotic pressure difference between the two sets of drops, water diffuses through the oil from the lower $\mathrm{NaCl}$ concentrations to the higher ones making the volume of the drops, which is measured overt time, change. Also, diffusion of water between two sets of nanoliter aqueous drops can be utilized in structural biology to perform high-throughput screenings of protein crystallization conditions inside the drops [40, 41]. In chemistry, the fusion of alternating drops by passive methods using the channel geometry and liquid phase flow allows the rapid production of supersaturated solutions of $\mathrm{Cd}^{2+}$ and $\mathrm{S}^{2-}$ ions to form CdS nanoparticles [42]. Taking advantage of the lasing effect occurring through whispering gallery modes when a dye inside a drop is optically excited, trains of drops of alternating dye solutions offer clever ways to engineer multi-color fast-switching microfluidic droplet dye lasers [43]. Also, alternating trains made of gas bubbles (or droplets of mineral oil) and liquid reaction compartments subjected to back and forth motion are commonly used to perform high-throughput analyses of slow kinetic processes such as enzymatic reactions [44], bacterial growths [45, 46] and nanomaterial syntheses [47]. This strategy based on oscillatory rather than continuous segmented flows reduces the device footprint as a single sensing location is needed. It however requires to separate adjacent liquid reactors with drops of mineral oil or gas bubbles to prevent so-called traffic jams [48] and fusion of drops during detection.

To generate a train of drops of alternating composition, one can merge two periodic train of drops at a T-junction, all drops of a train having a composition different than that of the drops of the other train [see Fig. 1(a)]. Here, we investigate both theoretically and experimentally the production dynamics of such trains. We begin by presenting a discrete model that describes well the formation mechanism of a train. We then validate the predictions of the model with millifluidic experiments.

\section{Discrete model}

To predict the structure of $1 \mathrm{D}$ trains of alternating drops formed by merging two trains of droplets at a Tjunction, we use a discrete approach that is the basis of models of droplet traffic at a T-junction [49] and the encapsulation dynamics of drops in the production double emulsions with standard two-step microfluidic dripping techniques [50]. Building on these works, we neglect the 


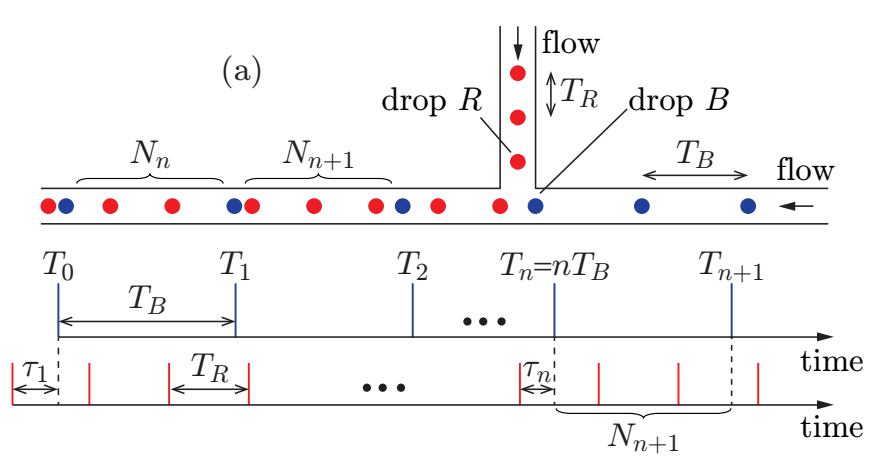

(b) sequence of alternating drops $B R R R B R R B R R B R R R B R R B R R B R R R B R R B R R R B R R B R R B .$. sequence of $N^{\max } N^{\min }$ drops $R \quad\left[N_{n}\right]:\left[\begin{array}{llllllllllll}3 & 2 & 2 & 3 & 2 & 2 & 3 & 2 & 3 & 2 & 2 & 3 \ldots\end{array}\right]$

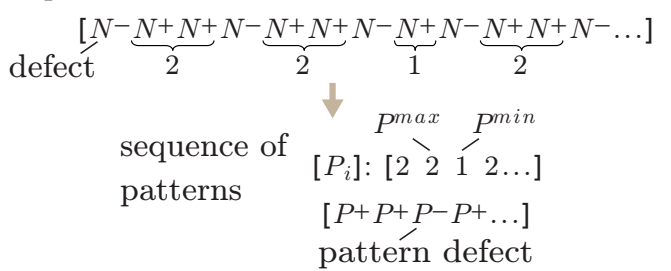

FIG. 1. (a) Schematic defining the variables at play in the modeled formation of $1 \mathrm{D}$ trains of alternating drops denoted $R$ and $B$ created by merging two periodic trains respectively made of drops $R$ and $B$ at a T-junction. (b) Outcomes of the model for a typical sequence of drops.

physical volume of drops. To distinguish the two sets of drops composing a train of alternating droplets, each drop of a set is designated by a letter, either $R$ or $B$. The drops $R$ and $B$ periodically reach the T-junction with periods $T_{R}$ and $T_{B}>T_{R}$, respectively [51]. In our model, the times at which the $n$-th $\operatorname{drop} B$ and the $k$-th droplet $R$ reach the junction are respectively $T_{n}=n T_{B}$ and $t_{k}=k T_{R}-\tau_{1}$ with $\tau_{1}<T_{R}$ (see Fig. 1(a) defining variables at play). Under these conditions, one can readily show that the following set of two recursive equations fully describes the formation dynamics of a train of alternating drops as it predicts the number $N_{n}$ of drops $R$ flowing between the $n$-th and $(n+1)$-th droplets $B$ :

$$
\begin{gathered}
N_{n}=\text { floor }\left(T_{B} / T_{R}-1+X_{n}\right)+1, \\
X_{n+1}=X_{n}+T_{B} / T_{R}-N_{n},
\end{gathered}
$$

with $X_{n}=\tau_{n} / T_{R}$ the time in $T_{R}$ units elapsed between the arrival at the junction of the last drop $R$ placed between the $(n-1)$-th and the $n$-th drops $B$ of a sequence.

The set of eqn (1) and (2) is similar to that of [50] describing the structure of double emulsions produced with two-step microfluidic techniques. Hence, the structure these fluid systems is isomorphic to that of the trains of alternating drops studied here and the generic properties below are common to both problems; a complete derivation of these dynamical properties can be found in [50]:

$\left(\mathrm{P}_{1}\right)$ The mean number of droplets $R$ placed between two consecutive drops $B$ is $\bar{N}=T_{B} / T_{R}$.

$\left(\mathrm{P}_{2}\right)$ Variations in the number of drops $R$ placed between two consecutive droplets $B$ do not exceed one unity as $N_{n}$ can take only two values: $N^{\max }=\operatorname{ceil}(\bar{N})$ or $N^{\text {min }}=$ floor $(\bar{N})$.

$\left(\mathrm{P}_{3}\right)\left|\frac{T_{B}}{T_{R}}-\operatorname{round}\left(\frac{T_{B}}{T_{R}}\right)\right|=\mathcal{F}\left(N^{-}\right)$is the fraction of defects in a sequence $\left[N_{n}\right]$. A defect denoted $N^{-}$corresponds to the variable $N^{\min }$ or $N^{\max }$ occurring the less often in $\left[N_{n}\right]$. Conversely, $N^{+}=\operatorname{round}(\bar{N})$ denotes the variable $N^{\min }$ or $N^{\max }$ appearing the more often in $\left[N_{n}\right]$.

When $T_{B} / T_{R}$ is not an integer, fluctuations of the number of drops $R$ between two consecutive drops $B$ is necessarily observed. Yet, one can establish generic properties describing the occurrence of defects in trains of alternating drops by processing the signal $\left[N_{n}\right]$ into a sequence of patterns $\left[P_{i}\right]$, a pattern corresponding to the number of $N^{+}$between two consecutive $N^{-}$in $\left[N_{n}\right]$ (see Fig. 1(b)].

$\left(\mathrm{P}_{4}\right)$ Two defects do not appear consecutively in a train of alternating drops.

$\left(\mathrm{P}_{5}\right)$ A train of alternating droplets is necessarily aperiodic whenever $T_{B}$ and $T_{R}$ are incommensurate.

$\left(\mathrm{P}_{6}\right)$ When $T_{B}$ and $T_{R}$ are commensurate, the structure of a train of alternating drops is periodic. Then, $T_{B} / T_{R}$ can be expressed as the irreducible fraction $p / q$ with $p$ and $q$ two integers. The period of $\left[N_{n}\right]$, that is, the number of drops $B$ minus 1 per cycle is then equal to $p$ while $q$ represents the number of patterns per cycle.

$\left(\mathrm{P}_{7}\right)$ Variations in the number of drops $R$ per pattern do not exceed one unity as $P_{i}$ is either $P^{\text {min }}=$ floor $\left(\frac{1}{|\varepsilon|}\right)-$ 1 or $P^{\max }=\operatorname{ceil}\left(\frac{1}{|\varepsilon|}\right)-1$ with $\epsilon=\bar{N}-N^{+}$.

$\left(\mathrm{P}_{8}\right) \bar{P}=\frac{1}{|\varepsilon|}-1$ is the mean number of drops $R$ per pattern.

$\left(\mathrm{P}_{9}\right)\left|\frac{1}{|\varepsilon|}-\operatorname{round}\left(\frac{1}{|\varepsilon|}\right)\right|=\mathcal{F}\left(P^{-}\right)$is the fraction of pattern defects, i.e., the patterns denoted $P^{-}$containing the less repeated number of $N^{+}$in a sequence $\left[P_{i}\right]$. Conversely, $P^{+}=\operatorname{round}(\bar{P})$.

$\left(\mathrm{P}_{10}\right)$ Pattern defects do not appear consecutively in a sequence $\left[P_{i}\right]$.

Interestingly, all the above properties are independent of the initial condition $\tau_{1}$ and they are fully described by the ratio $T_{B} / T_{R}$. This important feature will allow us to compare theoretical predictions to experimental results.

\section{Experiments}

To validate the theoretical predictions presented above, we conduct experiments with a millifluidic setup consisting of three T-junctions connected to one another by 
commercial tubes as shown in Fig 2(a). We first generate two independent periodic trains made of monodisperse water-in-oil droplets with two of the T-junctions. The trains then merge at the third junction which produces a train of alternating drops [Fig 2(b)].
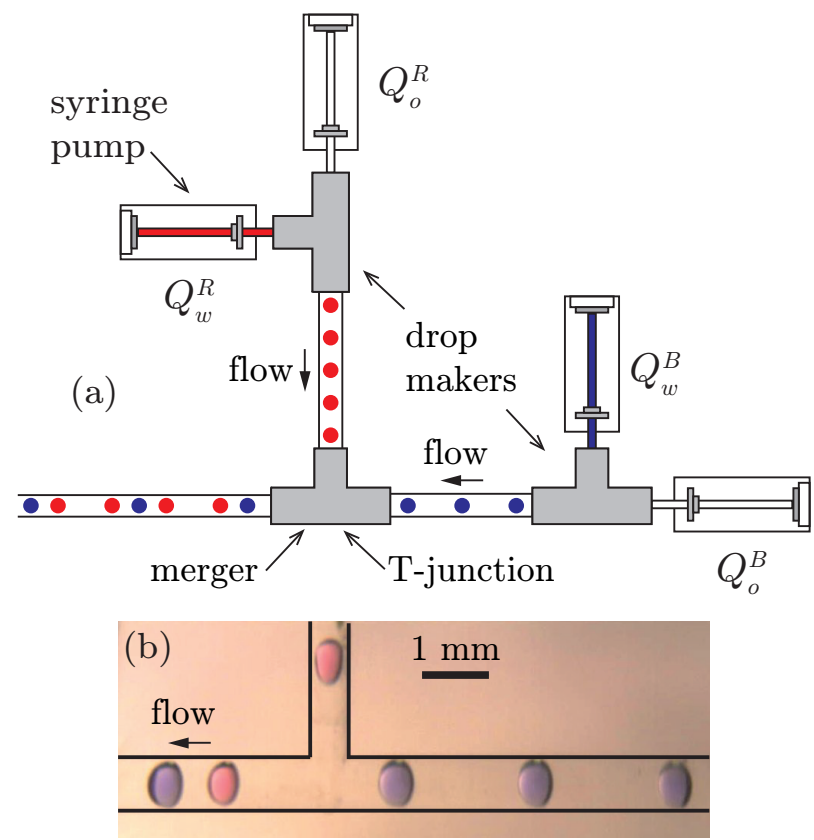

FIG. 2. (a) Schematic of the setup used to generate trains of alternating drops. (b) Image of the flow at a T-junction.

The continuous phase (sunflower oil purchased from Leader Price, France) and the dispersed aqueous phase (water colored by a blue or a red ink) are infused at constant flow rates through the two inlets of the drop makers. The flow rates are controlled independently using four syringe pumps (Harvard Apparatus PHD 2000). The water is colored to distinguish the $-\operatorname{red}(R)$ or blue $(B)-$ drops emitted by each of the two drop makers, $Q_{w}^{R}$ and $Q_{w}^{B}$ denoting their respective flow rates [see Fig 2(a)]. We also define $Q_{o}^{B}$ and $Q_{o}^{R}$, the flow rates of the oil infused through the two drop makers to form trains of drops $B$ and $R$, respectively. A camera (EO-1312C, Edmund Optics) records the arrivals of these drops at the $\mathrm{T}$-junction where the two trains meet. We analyze the videos with a custom-written software developed with MATLAB to obtain experimental sequences $\left[N_{n}\right]$ and $\left[P_{i}\right]$, periods $T_{R}$ and $T_{B}$ and drop volumes $\Omega^{R}=Q_{w}^{R} T_{R}($ drops $R$ ) and $\Omega^{B}=Q_{w}^{B} T_{B}$ (drops $\left.B\right)$. We work with constant values of $Q_{o}^{B}, Q_{w}^{B}$, and $Q_{w}^{R}$ and we vary $Q_{o}^{R}$ so that $T_{B}$ and $\Omega^{B}$ are fixed while $T_{R}$ and $\Omega^{R}$ are continuously adjusted.

For each experiment, a sequence $\left[N_{n}\right]$ consists of 100 analyzed alternating drops. Experimental findings are then compared to the predicted dynamical properties [items $\left.\left(\mathrm{P}_{1}\right)-\left(\mathrm{P}_{10}\right)\right]$ of the system. In our experiments, the initial condition $\tau_{1}$ is not controllable but we can val-
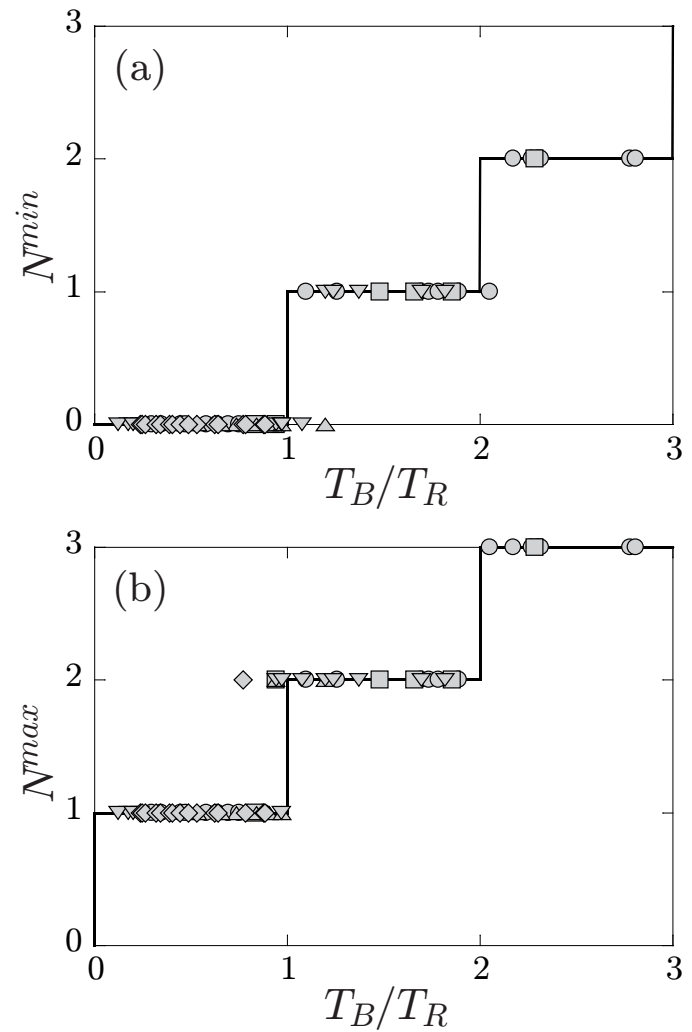

FIG. 3. Experimental variations of (a) $N^{\text {min }}$ and (b) $N^{\max }$ with $T_{B} / T_{R}$ for different volumes $\Omega^{R}$ : (॰) $0.175 \mu \mathrm{L},(\square)$ $0.158 \mu \mathrm{L},(\Delta) 0.123 \mu \mathrm{L},(\nabla) 0.10 \mu \mathrm{L}$ and $(\$) 0.07 \mu \mathrm{L}$. The symbols are identical in all figures. The lines are predictions from item $\left(\mathrm{P}_{2}\right)$.

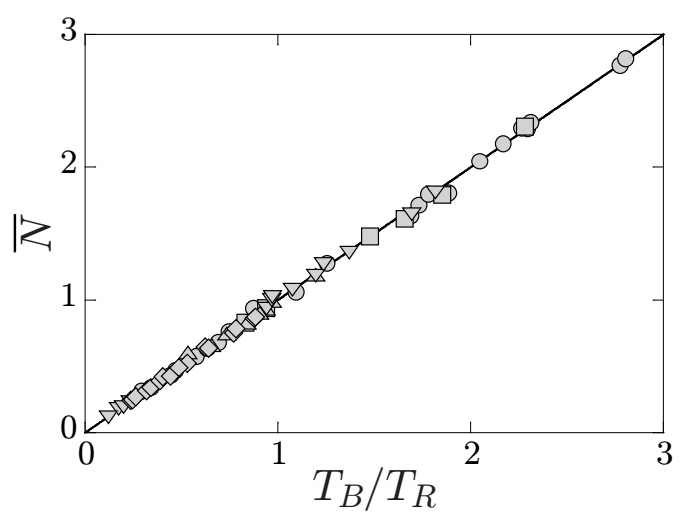

FIG. 4. Experimental variations of $\bar{N}$ with $T_{B} / T_{R}$. The line stands for the predicted property $\left(\mathrm{P}_{1}\right)$.

idate our theoretical predictions with experiments as $\tau_{1}$ has no effect on our modeling work.

Since the predicted period of a sequence $\left[N_{n}\right]$ is a nonanalytical function of $T_{B} / T_{R}$, the properties $\left(\mathrm{P}_{5}\right)$ and $\left(\mathrm{P}_{6}\right)$ cannot be validated experimentally as it would require analyzing an infinite number of drops. By con- 


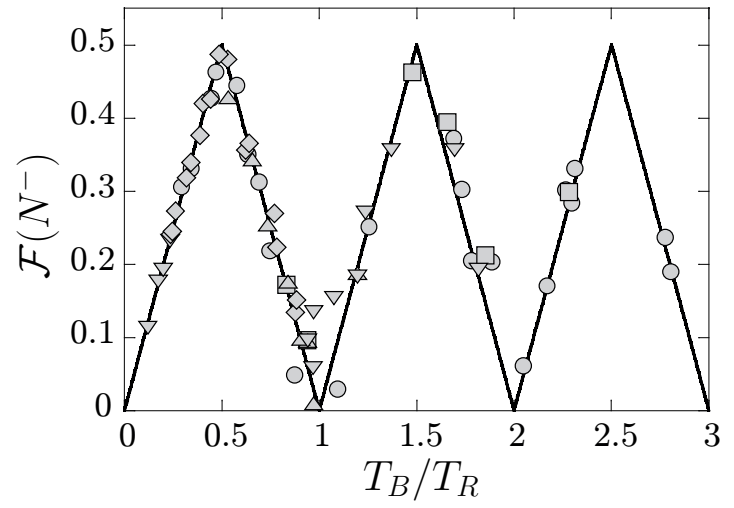

FIG. 5. Experimental variations of $\mathcal{F}\left(N^{-}\right)$with $T_{B} / T_{R}$. The solid line is calculated using item $\left(\mathrm{P}_{3}\right)$.
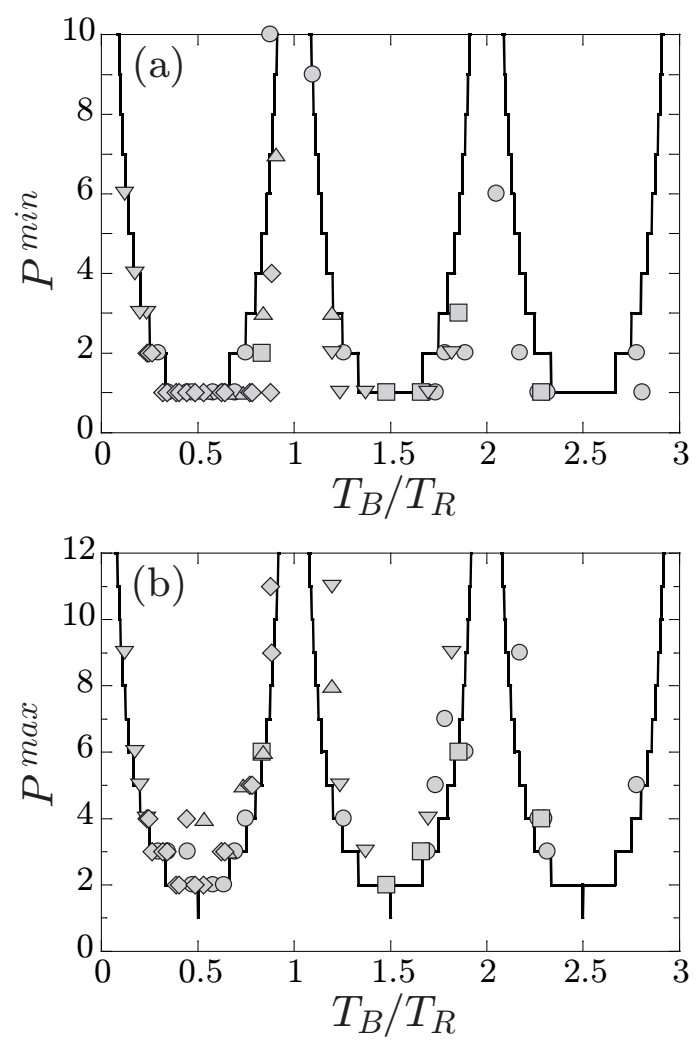

FIG. 6. Experimental evolution of (a) $P^{\min }$ and (b) $P^{\max }$ with $T_{B} / T_{R}$. The lines are predictions discussed in item $\left(\mathrm{P}_{7}\right)$.

trast, the observation of experimental videos over large sequences of alternating drops allows us to validate items $\left(\mathrm{P}_{4}\right)$ and $\left(\mathrm{P}_{10}\right)$ predicting that two defects do not appear consecutively in sequences of either alternating drops or patterns. Also, the variations with $T_{B} / T_{R}$ of $N^{\text {min }}$, $N^{\max }, \bar{N}$, and the fraction of defect $\mathcal{F}\left(N^{-}\right)$are well described by the properties $\left(\mathrm{P}_{1}\right)-\left(\mathrm{P}_{3}\right)$ [experiments are compared to predictions from Fig. 3 through Fig. 5].

Processing the signal $\left[N_{n}\right]$ into a pattern sequence $\left[P_{i}\right]$,

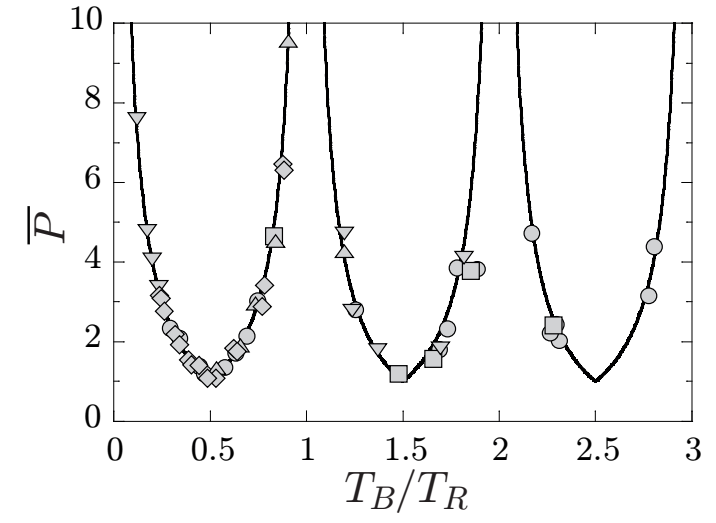

FIG. 7. Experimental variations of $\bar{P}$ with $T_{B} / T_{R}$. The lines predictions calculated using discussed $\left(\mathrm{P}_{8}\right)$.

our results show that variations of $P^{\text {min }}$ and $P^{\max }$ with $T_{B} / T_{R}$ concur well with item $\left(\mathrm{P}_{7}\right)$ (Fig. 6). However, we observe that the experimental variations of $P_{i}$ may exceed one unity. This discrepancy between predictions and experiments likely arises from fluctuations of the flow rates that are inherent in our experiment. We also find a good agreement between the prediction $\left(\mathrm{P}_{8}\right)$ and the experimental variations of $\bar{P}$ with $T_{B} / T_{R}$ (Fig. 7).

\section{Conclusion}

We have shown that a recent model of the two-step microfluidic production of double emulsions can describe the structure of $1 \mathrm{D}$ trains of alternating drops formed by merging two periodic droplet trains at a T-junction. Although this discrete model neglects the physical volumes of drops, it well describes our experiments conducted for different droplet volumes. The predicted and observed commensurability-driven structural defects are inherent in the studied trains of alternating drops. Our results should offer robust ways to engineer such trains that are used in a wide variety of applications.

Acknowledgements: This work was supported by the Brittany Region of France and le Fond Européen de Développement Régional (FEDER). H. Maruoka thanks TUAT for granting him a fellowship to work at IPR.

[1] S. L. Anna, N. Bontoux and H. A. Stone, Appl. Phys. Lett., 2003, 82, 364-366.

[2] R. K. Shah, H. C. Shum, A. C. Rowat, D. Lee, J. J. Agresti, A. S. Utada, L. Y. Chu, J.-W. Kim, A. Fernandez-Nieves, C. J. Martinez and D. A. Weitz, Mater. Today, 2008, 11, 18-27. .

[3] M. Joanicot and A. Ajdari, Science, 2005, 309, 887-888. 
[4] S.-Y. Teh, R. Lin, L.-H. Hung and A. P. Lee, Lab Chip, 2008, 8, 198-220.

[5] P. Garstecki, M. J. Fuerstman, H. A. Stone and G. M. Whitesides, Lab Chip, 2006, 6, 437-446.

[6] A. R. Abate, P. Mary, V. van Steijn and D. A. Weitz, Lab Chip, 2012, 12, 1516-1521.

[7] T. Glawdel, C. Elbuken and C. L. Ren, Phys. Rev. E, 2012, 85, 016322 .

[8] W. Engl, M. Roche, A. Colin, P. Panizza and A. Ajdari, Phys. Rev. Lett., 2005, 95, 208304.

[9] L. Prat, F. Sarrazin, J. Tasseli and A. Marty, Microfluid Nanofluid, 2006, 2, 271-274.

[10] H. Song, M. R. Bringer, J. D. Tice, C. J. Gerdts and R. F. Ismagilov, Appl. Phys. Lett., 2003, 83, 4664-4666.

[11] M. Muradoglu and H. A. Stone, Phys Fluids, 2005, 17, 073305.

[12] R. O. Grigoriev, M. F. Schatz and V. Sharma, Lab Chip, 2006, 6, 1369-1372.

[13] M. Rhee and M. A. Burns, Langmuir, 2008, 24, 590-601.

[14] J. U. Shim, G. Cristobal, D. R. Link, T. Thorsen, Y. Jia, K. Piattelli and S. Fraden, J. Am. Chem. Soc., 2007, 129, 829-834.

[15] P. Laval, N. Lisai, J. B. Salmon and M. Joanicot, Lab Chip, 2007, 7, 829-834.

[16] W. Shi, J. Qin, N. Ye and B. Lin, Lab Chip, 2008, 8, 1432-1435

[17] S. S. Bithi and S. A. Vanapalli, Soft Matter, 2015, 11, $5122-5132$

[18] D. R. Link, S. L. Anna, D. A. Weitz and H. A. Stone, Phys. Rev. Lett., 2004, 92, 054503.

[19] L. Ménétrier-Deremble and P. Tabeling, Phys. Rev. E: Stat., Nonlinear, Soft Matter Phys., 2006, 74, 035303R.

[20] M. de Menech Phys. Rev. E: Stat., Nonlinear, Soft Matter Phys., 2006, 73, 031505.

[21] T. Cubaud, Phys. Rev. E: Stat., Nonlinear, Soft Matter Phys., 2009, 80, 026307).

[22] L. Salkin, L. Courbin and P. Panizza, Phys. Rev. E: Stat., Nonlinear, Soft Matter Phys., 2012, 86, 036317.

[23] K. Ahn, C. Kerbage, T. P. Hunt, R. M. Westervelt, D. R. Link and D. A. Weitz, Appl. Phys. Lett., 2006, 88, 024104

[24] C. N. Baroud, J.-P. Delville, F. Gallaire and R. Wunenburger, Phys. Rev. E: Stat., Nonlinear, Soft Matter Phys., 2007, 75, 046302.

[25] H. Maenaka, M. Yamada, M. Yasuda and M. Seki, Langmuir, 2008, 24, 4405-4410.

[26] M. Chabert, K. D. Dorfman and J.-L. Viovy, Electrophoresis, 2005, 26, 3706-3715.

[27] D. R. Link, E. Grasland-Mongrain, A. Duri, F. Sarrazin, Z. Cheng, G. Cristobal, M. Marquez and D. A. Weitz, Angew. Chem. Int. Ed., 2006, 45, 2556-2560.

[28] Y.-C. Tan, Y. L. Ho and A. P. Lee, Microfluid Nanofluid, 2007, 3, 495-499.
[29] N. Bremond, A. R. Thiam and J. Bibette, Phys. Rev. Lett., 2008, 100, 024501.

[30] Y.-C. Tan, J. S. Fisher, A. I. Lee, V. Cristini and A. P. Lee, Lab Chip, 2004, 4, 292-298.

[31] V. Trivedi, A. Doshi, G. K. Kurup, E. Ereifej, P. J. Vandevord and A. S. Basu Lab Chip, 2010, 10, 2433-2442.

[32] M. G. Pollack, A. D. Shenderov and R. B. Fair, Lab Chip, 2002, 2, 96-101.

[33] S. Haeberle and R. Zengerle, Lab Chip, 2007, 7, 10941110 .

[34] C. N. Baroud, M. Robert de Saint Vincent and J.-P Delville, Lab Chip, 2007, 7, 1029-1033.

[35] R. Seemann, M. Brinkmann, T. Pfohl and S. Herminghaus, Rep. Prog. Phys., 2012, 75, 016601.

[36] S. Okushima, T. Nisisako, T. Torii and T. Higuchi, Langmuir, 2004, 20, 9905-9908.

[37] P. Panizza, W. Engl, C. Hany and R. Backov, Colloids Surf., A, 2008 312, 24-31.

[38] A. Schmit, L. Courbin, M. Marquis, D. Renard and P. Panizza, RSC Adv., 2014, 4, 28504-28510.

[39] F. Leal-Calderon, V. Schmitt and J. Bibette, Emulsion Science: Basic Principles (Springer-Verlag Ed., 2nd version, 2007).

[40] B. Zheng, J. D. Tice, L. S. Roach and R. F. Ismagilov, Angew. Chem. Int. Ed., 2004, 43, 2508-2511.

[41] B. Zheng, J. D. Tice and R. F. Ismagilov, Anal. Chem., 2004, 76, 4977-4982.

[42] L.-H. Hung, K. M. Choi, W.-Y. Tseng, Y.-C. Tan, K. J. Shea and A. P. Lee, Lab Chip, 2006, 6, 174-178.

[43] S. K. Y. Tang, Z. Li, A. R. Abate, J. J. Agresti, D. A. Weitz, D. Psaltis and G. M. Whitesides, Lab Chip, 2009, 9, 2767-2771.

[44] F. Gielen, L. van Vliet, B. T. Koprowski, S. R. A. Devenish, M. Fischlechner, J. B. Edel, A. J deMello and F. Hollfelder, Anal. Chem., 2013, 85, 4761-4769.

[45] L. Baraban, F. Bertholle, M. L. M. Salverda, N. Bremond, P. Panizza, J. Baudry, J. Arjan G. M. de Visser and J. Bibette, Lab Chip, 2011, 11, 4057-4062.

[46] S. Jakiela, T. S. Kaminski, O. Cybulski, D. B. Weibel and P. Garstecki, Angew. Chem. Int. Ed., 2013, 52, 89088911.

[47] M. Abolhasani, A. Oskooei, A. Klinkova, E. Kumacheva and A. Gunther Lab Chip, 2014, 14, 2309-2318.

[48] N. Champagne, R. Vasseur, A. Montourcy and D. Bartolo, Phys. Rev. Lett., 2010, 105, 044502.

[49] D. A. Sessoms, A. Amon, L. Courbin and P. Panizza, Phys. Rev. Lett., 2010, 105, 154501.

[50] A. Schmit, L. Salkin, L. Courbin and P. Panizza, Soft Matter, 2014, 10, 4743-4748.

[51] The model is discussed in the case $T_{B}>T_{R}$ for which at least one drop $R$ is placed between two drops $B$ a sequence $\left[N_{n}\right]$ but theoretical and experimental results in the case $T_{B}<T_{R}$ are also presented. 